\title{
FPCにおける回路設計が伝送特性に与える影響
}

\author{
笹岡 典史 ${ }^{*}$, 大野 正人*
}

\section{The Effect of Circuit Pattern Design on Transmission Characteristics at FPC}

\author{
Norifumi SASAOKA* and Masato OONO*
}

*ニッポン高度紙工業株式会社デバイス技術部（テ781-0395 高知県高知市春野町弘岡上648）

*Device Engineering Department, Nippon Kodoshi Corp. (648 Hirooka-kami, Haruno-cho, Kochi-shi, Kochi 781-0395)

\begin{abstract}
In this paper, a FPC which has high flexibility and low insertion losses was investigated. We made several kinds of our original FPC which are constructed with Microstrip-Lines or Strip-Lines when changing various factors. These factors are the shape of the GND pattern, the width of the signal pattern, the thickness of the copper, and the thickness of the resin. We confirmed that the stability of the characteristic impedance and the S-parameter change form the shape of the GND pattern. An equilateral triangle GND pattern causes a circuit resonance. We concluded from the characteristic impedance and S-parameter data that a square is the best shape for the GND pattern and it is better to make the resin thicker and to extend the pattern width.
\end{abstract}

Key Words: FPC, Microstrip-Line, Strip-Line, Characteristic Impedance, S-parameter

\section{1. 緒 言}

パソコンやモバイル機器, $\mathrm{AV}$ 機器における性能向上に 伴い，プリント配線板上の信号は高速化の一途をたどって いる。特に信号周波数が数百 $\mathrm{MHz} \sim \mathrm{GHz}$ 領域になると, 従 来のフレキシブルプリント配線板（=以下 FPC）では，信 号の損失が大きく使用困難となる ${ }^{1), 2)}$ 。損失の課題を解決す るためには, FPCの絶縁層や導体材料, パターン設計を最 適化することにより損失を軽減する必要がある ${ }^{1), 2)}$ 。だが, それらの検討において, 本来FPCに求められる薄さと柔軟 性は損なってはならない。

本稿では, FPCの線路構造, GND パターン形状に主な焦 点をあて FPCの伝送特性を評価した。その結果をもとに FPC に打ける回路設計が伝送特性に与える影響について報 告する。

\section{2. 評価用 FPC}

Fig. 1 に伝送特性評価用 FPCの概略図を示す。長さ $200 \mathrm{~mm}$ の信号ラインと測定用ランドからなり, FPC は長さ $200 \mathrm{~mm}$, 幅 $20 \mathrm{~mm}$ の寸法に 1 枚ずつ外形加工している。測 定用ランド部は，信号ラインをGNDで挟んだ形状で，上 下の GND 層は導電性ペーストの埋め込みVIA で接続され ている。絶縁層はわれわれの開発した比誘電率 $2.4 \sim 2.9$, 誘
電正接 $0.007 \sim 0.008$ のポリアミドイミド樹脂である。製造 方法は，樹脂層をスクリーン印刷にて形成し銅箔を積層す るビルドアップ法である。

本FPCの特長は，銅箔と樹脂のみで構成でき，接着剂な どの異質な媒質をもたないこと，樹脂の厚みを調整できる ことの 2 点である。

評価用 FPC は，GND パターンの残銅率を $50 \%$ と定めて 形状を変化させたほか，線路構造，信号ライン幅，層間樹 脂厚み，銅箔なども変化させた数十種類を作製した。

\section{3. 評価方法}

3.1 特性インピーダンス

アジレント・テクノロジー製 TDR 測定器 86100C, 測定 用プローブCP960-01を用いて，信号立ち上がり時間 $100 \mathrm{ps}$ の条件で特性インピーダンスの測定を行った。

\section{2 伝送特性}

特性インピーダンスが $50 \pm 5 \Omega$ のサプルを抽出し，ア ジレント・テクノロジー製ベクトルネットワークアナライ ザ N5230A，測定用プローブには， $40 \mathrm{GHz}$ まで対応のカス ケード・マイクロテック製コプレナプローブB90-122391を 用いて Sパラメータ測定を行った。測定前の校正方法は, 同社製の校正基板 K00-41702 を使用し SOLT法により実施 した。測定系を Fig. 2 に示す。 


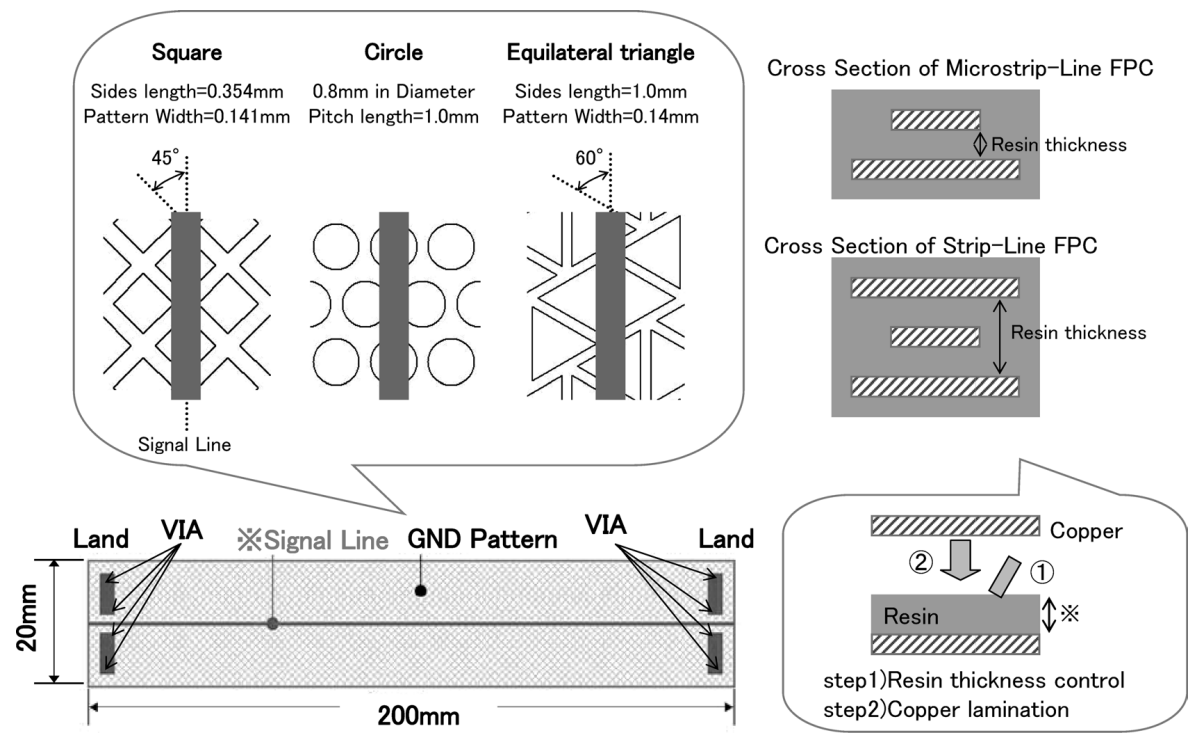

Fig. 1 Schematic illustration of FPC

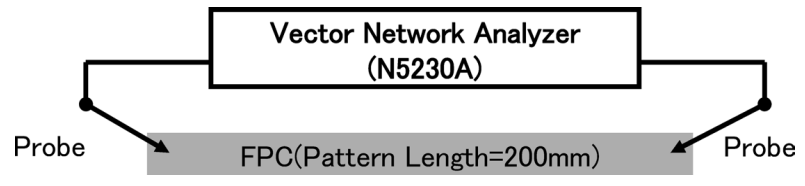

Fig. 2 Illustration of measurement system

\section{4. 評価結果}

\section{1 特性インピーダンス}

Fig. 3 において，マイクロストリップラインでの各 GND パターン形状に対する特性インピーダンスを示す。Fig. 4 において，ストリップラインでの特性インピーダンスを示 す。

グラフの横軸は層間樹脂厚みで，マイクロストリップラ イン FPC は信号ラインと GND 間，ストリップライン FPC は GND 間の厚みである。縦軸は特性インピーダンスの值であ る。いずれにおいても，配線幅が狭くなると特性インピー ダンスのバラツキが大きい傾向にある。特に正三角形品は 他と比較してバラツキが大きく, 配線幅が $100 \mu \mathrm{m}$ 以下では $\pm 10 \Omega$ 程度のバラッキとなる。メッシュ形状品およびメッ シュ形状とコプレナ線路組み合わせ品は, バラツキが小さ く，いずれの配線幅においても $5 \Omega$ の範囲内にあり，配 線幅 $120 \mu \mathrm{m}$ においては $\pm 3 \Omega$ の範囲内にあることが確認さ れた。

\section{2 伝送特性}

次に，特性インピーダンスが $50 \pm 5 \Omega$ のンプルを抽出 し，Sパラメータ測定を行った。Fig. 5 において，GNDパ ターン形状変化に対する伝送損失の測定結果を示す。GND パターンの形状が正三角形の場合, いずれの線路構造にお いても，16 GHz近傍から損失が著しく大きくなり，19 GHz 以上の帯域で共振点が確認された。正三角形品以外はいず
れも大差は見られなかった。

続いて, GNDパターン形状をメッシュとし，信号ライン に使用する銅箔の表面粗度と厚みを変更したマイクロスト リップライン FPC およびストリップライン FPCを数種類作 製し，特性インピーダンス $50 \pm 5 \Omega$ 品の伝送損失の測定を 行った。結果をFig. 6 に示す。

線路構造と銅箔仕様により伝送損失に変化が見られた。 まず線路構造を比較するとマイクロストリップラインの方 がストリップラインよりも伝送損失が小さい。ストリップ ラインは上下に GND があるため表皮抵抗はマイクロスト リップラインの約半分になると考えられるが，信号ライン の上下面が樹脂で覆われている。一方，マイクロストリッ プラインは，信号ラインの片側面がGND，もう一方の面は 大気であるため，樹脂に比べ誘電率は小さく誘電損が軽減 される効果が考えられる。次に銅箔の仕様変化に着目する と，表面粗化銅䈃は表面平滑銅䇴に比べ伝送損失が大きい ことが確認できた。銅箔厚み変化に対しては，ストリップ ライン FPCはマイクロストリップライン FPCに比ベイン ピーダンス整合に必要な配線幅や層間樹脂厚みがより大き く変化するため，伝送損失の変化が大きくなったものと考 える。

\section{3 ストリップラインFPCの仕様最適化}

得られたデー夕を元に，現在われわれの製造している最 屯誘電率の低い樹脂 $\left(\varepsilon_{\mathrm{r}}=2.4, \tan \delta=0.007\right)$ と表面平滑圧延 銅箔 $16.5 \mu \mathrm{m}\left(R_{\mathrm{z}}=0.6 \mu \mathrm{m}\right)$ を使用し， GND パターンをメッ シュ形状として，ストリップライン FPCの仕様最適化を検 討した。結果を Fig. 7, Fig. 8 に示す。

配線幅 100 1 10 $\mu \mathrm{m}$ ，層間樹脂厚み 50 105 $\mu \mathrm{m}$ で特性イ ンピーダンス $50 \pm 5 \Omega$ 品が 4 種作製できた。 4 種の伝送損失 を測定した結果，配線幅，樹脂厚みの増加に伴い伝送損失 も低下する傾向が確認され，配線幅 $140 \mu \mathrm{m}$ ，層間樹脂厚み 


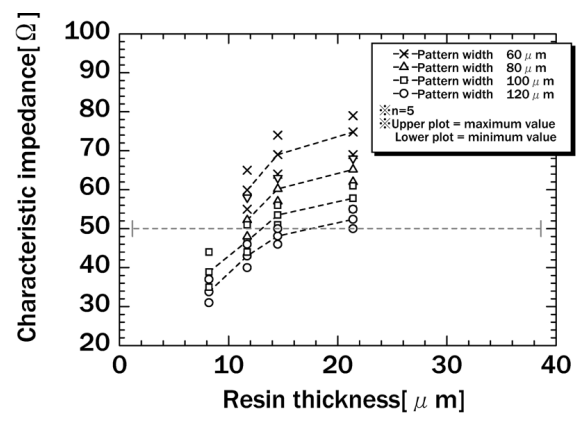

$\begin{array}{lllll}\text { Total thickness of FPC } & 54 & 63 & 69 & 76\end{array}$ [ $\mu \mathrm{m}]$

Circle GND pattern $\begin{array}{ccccc}\text { Total thickness of FPC } & 52 & 62 & 68 & 74\end{array}$

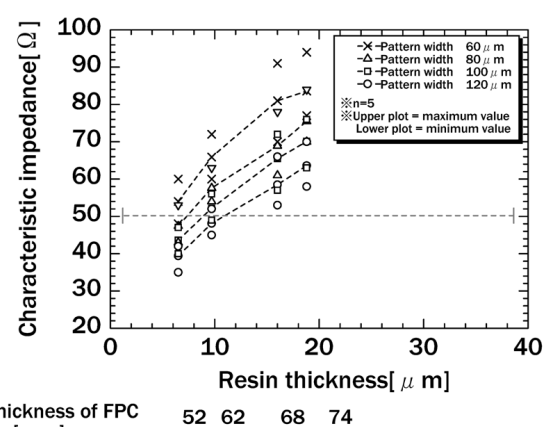

Equilateral triangle GND pattern
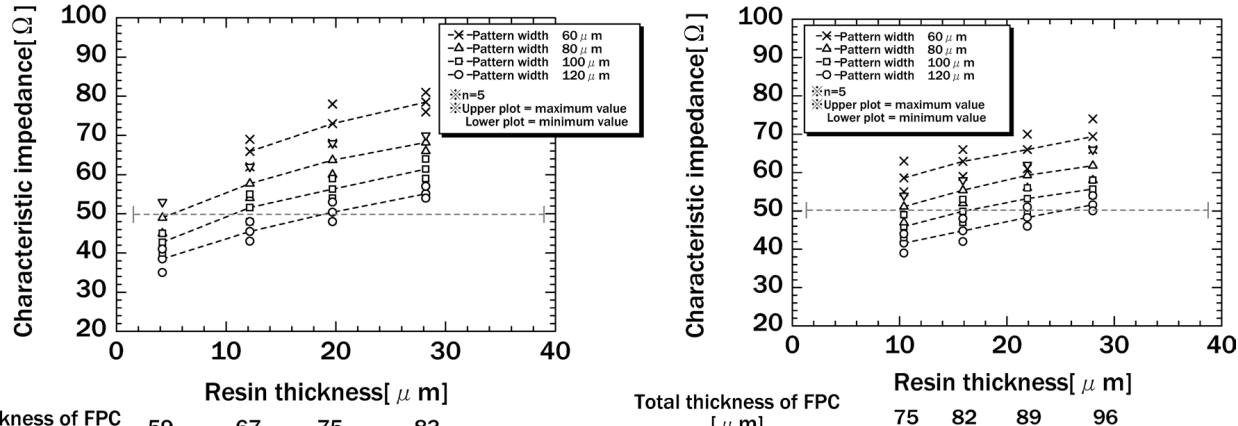

$[\mu \mathrm{m}]$

$\begin{array}{llll}75 & 82 & 89 & 96\end{array}$ Total thickness

$\begin{array}{lll}67 & 75 \quad 83\end{array}$

Square GND pattern

Square GND pattern and Coplanar

Fig. 3 Measured characteristic impedance depend on resin thickness at Microstrip-Line FPC
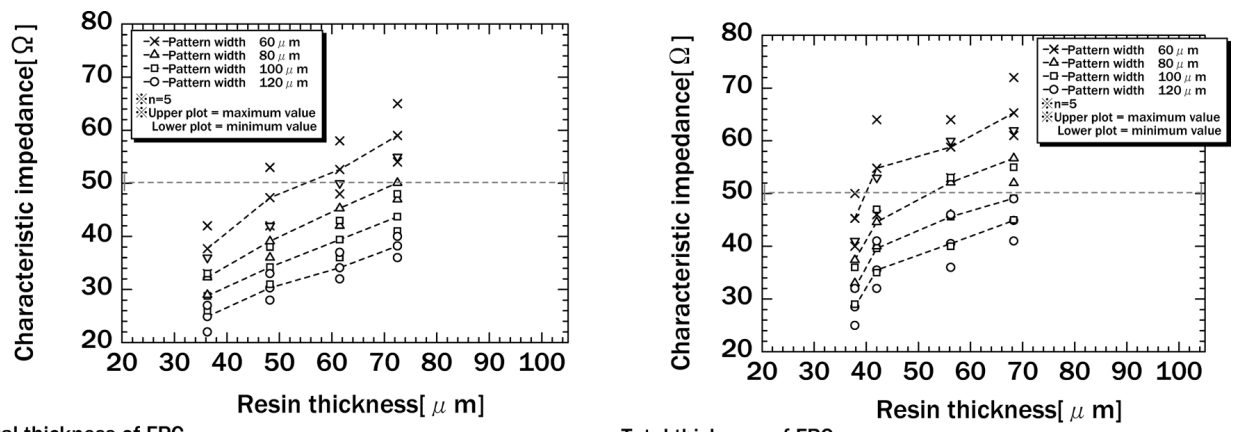

$\begin{array}{ccccc}\text { Total thickness of FPC } & 89 & 102 & 117 & 134\end{array}$

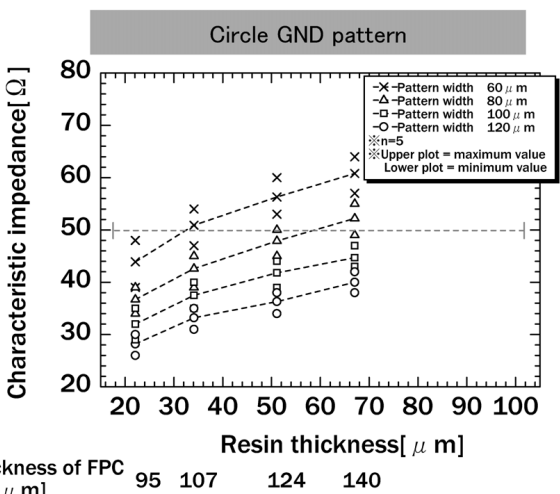

$\begin{array}{llll}\text { Total thickness of FPC } 95 & 107 & 124 & 140\end{array}$

Square GND pattern

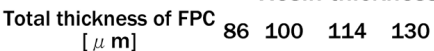

Equilateral triangle GND pattern

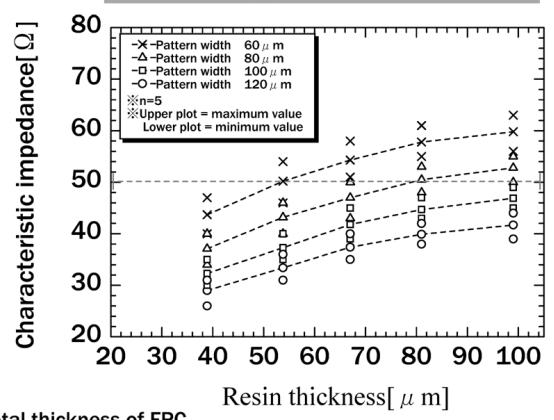

Total thickness of FPC $\begin{array}{lllll}101 & 116 & 131 & 149 & 165\end{array}$

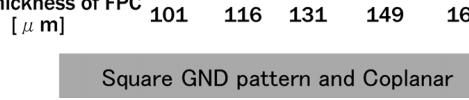

Fig. 4 Measured characteristic impedance depend on resin thickness at Strip-Line FPC 

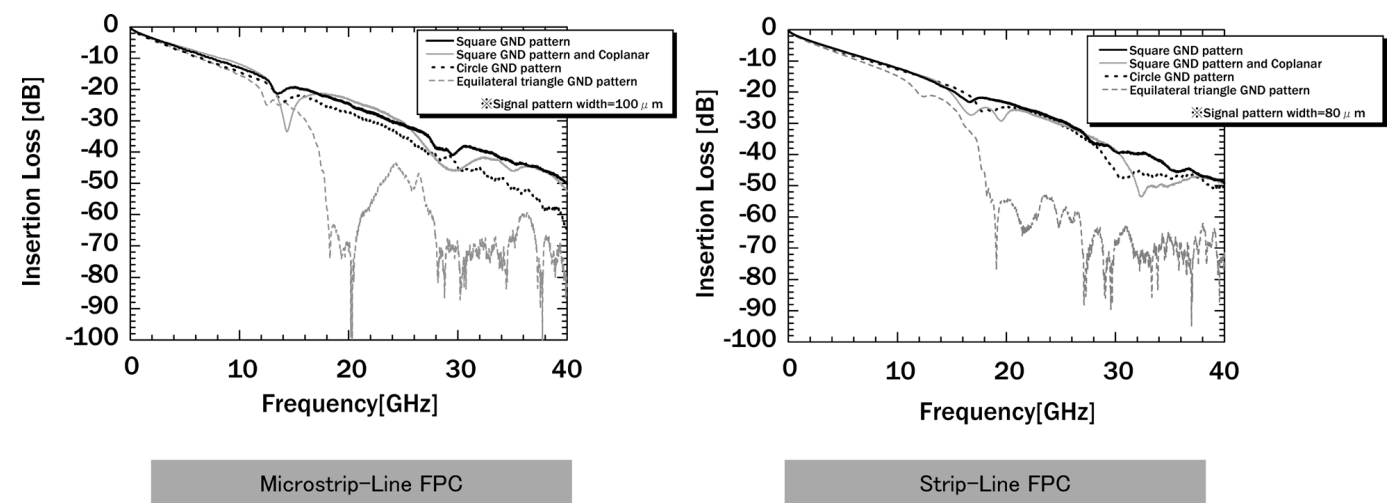

Fig. 5 Measured S-parameter effect of GND pattern
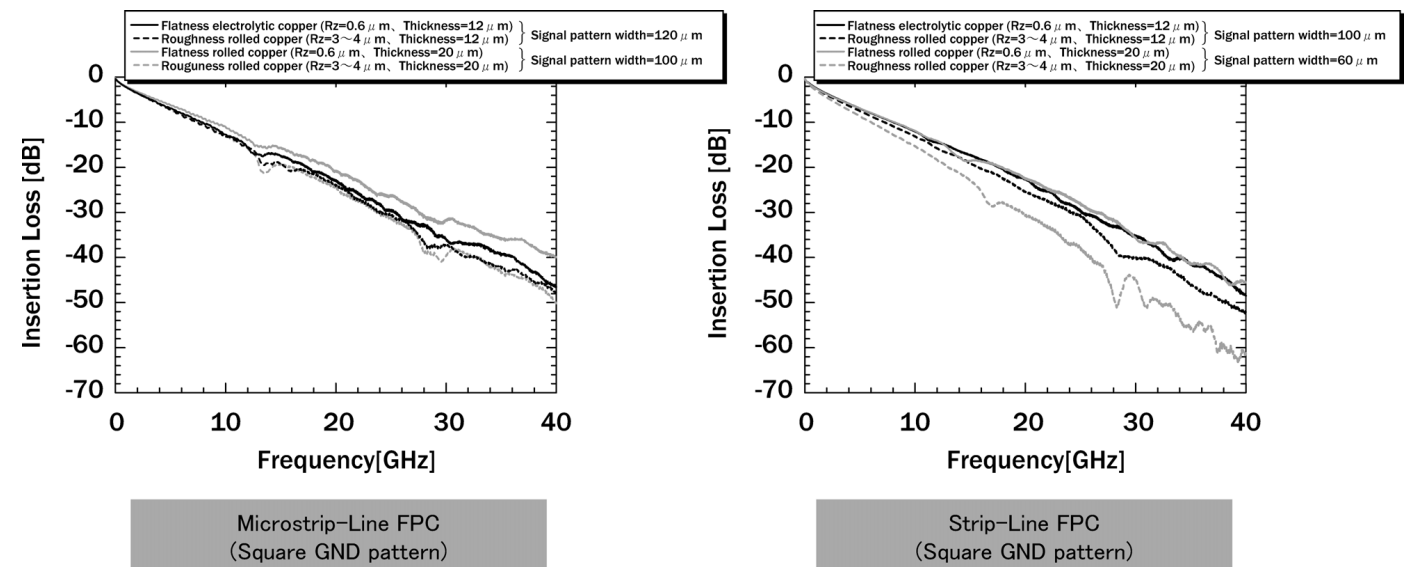

Fig. 6 Measured S-parameter effect of copper roughness and thickness

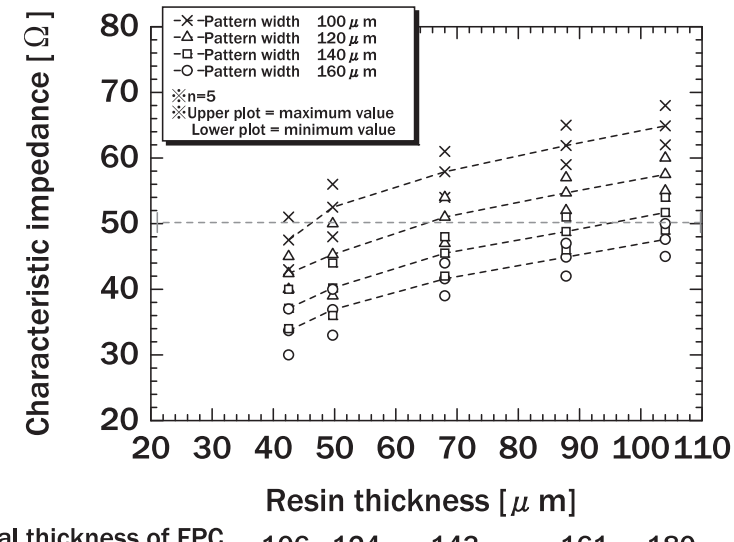

$\begin{array}{llllll}\text { Total thickness of FPC } & 106 & 124 & 143 & 161 & 180\end{array}$

$$
\text { [ } \mu \mathrm{m}]
$$

Fig. 7 Measured characteristic impedance depend on resin thickness at Strip-Line FPC (=Square GND pattern)

$104 \mu \mathrm{m}$ が最も伝送損失が小さく，3 $3 \mathrm{GHz}$ で $-3.2 \mathrm{~dB}, 6 \mathrm{GHz}$ で $-5.2 \mathrm{~dB}$ という值となった。

\section{5. 結 言}

フレキシブルプリント配線板において，数百 $\mathrm{MHz} \sim \mathrm{GHz}$ 領域の信号を伝送する際，FPCの柔軟性を損なうことなく, 課題となる伝送損失を軽減させるため, GNDパターン形

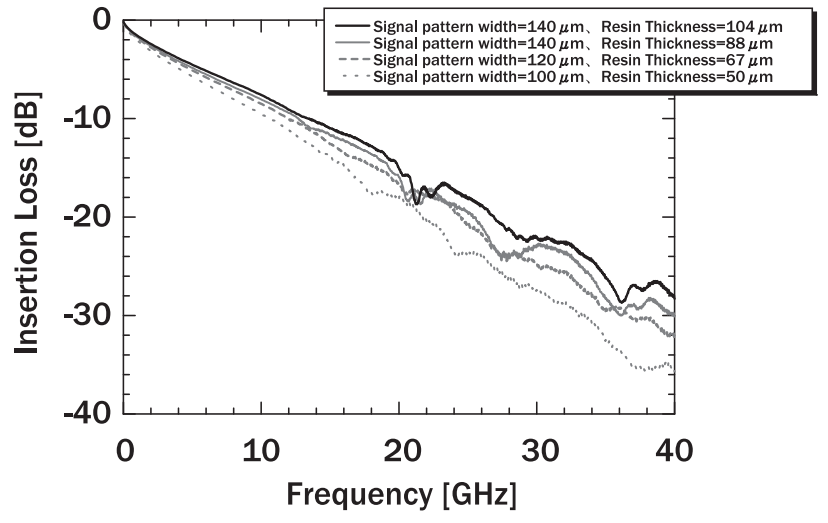

Fig. 8 Measured S-parameter at Strip-Line FPC (=Square GND pattern)

状，線路構造，信号ライン幅，層間樹脂厚み，銅箔などを 変化させた FPCを作製し評価した結果，以下のことがわ かった。

・線路構造については, 要求性能, FPCを設置する周辺の 状況，電磁環境両立性を考えて選択を行う。

・GND パターン形状はメッシュが適していると判断する。 正三角形形状では，特性インピーダンスの值が $10 \%$ の 範囲内に収まらない上に, 共振の発生やフィル夕回路之 なる可能性がある。 
・インピーダンスのバラツキ低減には，コプレナ線路構造 が有効であるが，伝送損失にはほとんど影響しない。

・伝送損失軽減のためには, 設計段階において, 表面粗度 の小さい銅箔を選択した後, 誘電損の軽減を第一に考 え, 比誘電率の小さい樹脂を選択し, 信号ライン幅, 層 間樹脂厚みを, 許容できる範囲内でできる限り大きくと ることが有効である。

\section{謝 辞}

本研究の遂行にあたり，FPCの設計および測定に関して，
エーイーティー上田様より多くのご助言をいただきました。 深く感謝申し上げます。

\section{文献}

1) 碓井有三 : “高速システム設計に扔ける線路損失の考え方, ” Design Wave Magazine, No. 70, pp. 48-55, 2003

2) 高橋 勉：“高速ディジタル・プリント配線板のノイズ対 策,”Design Wave Magazine, No. 68, pp. 84-95, 2003 